\title{
Rhenium Re-186 Hydroxyethylidene Diphosphonate
}

National Cancer Institute

\section{Source}

National Cancer Institute. Rhenium Re-186 Hydroxyethylidene Diphosphonate. NCI

Thesaurus. Code C1562.

An synthetic compound containing the org anic phosphonate hydroxyethylidene diphosphonate (HEDP) labeled with the radioisotope rhenium Re 186. Re-186 hydroxyethylidene diphosphonate binds to hydroxyapatite in bone, delivering a cytotoxic dose of beta radiation to primary and metastatic bone tumors. Re-186 is a beta emitter with a short half-life, a radioisotope profile that provides localized antitumor radiocytotoxicity while sparing extramedullary bone marrow tissues. 